\title{
LC-MS Method for Determining Amiodarone and Desethylaminodarone in Rat Plasma Used in Endog- enous Overdosing Conditions Following Lipolysis
}

\author{
George Jîtcă, Bianca-Eugenia Ősz*, Szende Vancea, Amalia Miklos, Amelia Tero-Vescan \\ University of Medicine and Pharmacy of Tîrgu Mureș, Romania
}

\begin{abstract}
Objective: The purpose of this study was to develop a LC-MS method to determine amiodarone (AMI) and its major metabolite desethylamiodarone (DEA) from rat plasma released from the adipose tissue of AMl treated rats subjected to a weight gain/weight loss cycle. Methods: Separation of the compounds was performed on a Kinetex $2.6 \mu \mathrm{m} \mathrm{C18} 100 \times 4.6 \mathrm{~mm}$ column under isocratic conditions using a mixture of acetonitrile: $0.1 \%$ formic acid $65: 35$ at a flow rate of $0.5 \mathrm{ml} / \mathrm{min}$. Detection of the analyte was performed by electrospray positive ionization, the monitored ions being $135 \mathrm{~m} / \mathrm{z}$ from 646 for AMl and $135 \mathrm{~m} / \mathrm{z}$ of 618 for DEA. Analytes were extracted after plasma protein precipitation with methanol. Results: The developed method presented specificity and linearity on the concentration range of $25-2500 \mathrm{ng} / \mathrm{ml}$ plasma for $\mathrm{AMl}$ and $2.5-1250 \mathrm{ng} / \mathrm{ml}$ plasma for DEA and the precision and accuracy of the method at all of quality control concentration levels including LLOQ were according to official guidelines for validating analytical methods. Conclusions: A sensitive and accurate LC-MS method has been developed with a much lower LLOQ than literature data to detect the plasma concentration differences of the studied analytes that result from forced lipolysis and mobilization from the adipose tissue.
\end{abstract}

Keywords: amiodarone, desethylamiodarone, rat, lipolysis

Received 28 June 2018 / Accepted 16 August 2018

\section{Introduction}

Amiodarone (AMI) is a compound with a particular pharmacodynamic and pharmacotoxicological profile among cardiovascular medication. In addition to antiarrhythmic action as a $\mathrm{K}^{+}$channel blocker, it also presents noncompetitive antagonistic action on alpha and beta receptors. In clinical practice, AMI is used to control ventricular and supraventricular tachycardia but also for the prevention of recurrences. AMI increases life expectancy in patients post myocardial infarction or suffering from congestive heart failure [1]. From the pharmacokinetic point of view, it has a variable oral absorption, a bioavailability of $22-86 \%$ and a high volume of distribution. The half-life is $5-20$ hours after a single dose, but is up to 58 days after a long-term treatment [2].

Desethylamiodarone (DEA) is the main metabolite of AMI and presents similar therapeutic and toxicological properties to AMI. Even if plasma concentrations of the metabolite are comparable to those of the active substance, in some tissues, there are differences in concentrations. Until the steady state is established, the active substance and the metabolite accumulate in the tissues. Long-term administration of AMI produces excessive accumulation through a mechanism that can not be explained by classical (single compartment model) pharmacokinetics and involves increasing tissue and plasma concentration by maintaining the initial dose. Nowadays, the use of AMI is often associated with a variety of adverse effects, causing

* Correspondence to: Bianca-Eugenia Ősz

E-mail: bianca.osz@umftgm.ro patient noncompliance because of the severe toxicity. Multiple organs are affected, including the lungs [3], liver [4], thyroid gland [5], neurological system, skin and gastrointestinal system. Some of these side effects are reversible, but severe cases have also been reported. The fundamental mechanism of AMI toxicity is not fully known, systemic toxic effects are supposed to be related to the accumulation of phospholipids in the target tissues [6].

Despite the multiple adverse effects, because of the low treatment cost, AMI is the antiarrhythmic of choice in ventricular and supraventricular tachycardia, but due to the tendency of cumulation in different organs, in case of intense lipolysis (diet with the aim of reducing body weight or forced in the case of a stroke or post-acute myocardial infarction) massive release from deposits can lead to exacerbation of adverse effects. Under these circumstances, the aim of the present study is to develop a sensitive and precise LC-MS method to determine AMI and DEA from rat plasma, that can quantify the excess of AMI and DEA released from the deposits in the adipose tissue, following lipolysis in obese animals treated with AMI .

\section{Materials and Methods}

\section{Chemicals, reagents, solvents}

AMI and DEA standards were purchased from Sigma Aldrich and were $>98 \%$ pure. Methanol, acetonitrile and formic acid of analytical grade were purchased from Merck KGaA (Darmstadt, Germany). Distilled water was obtained from a Millipore Direct Q system. 


\section{Preparation of standard solutions}

The AMI and DEA $1 \mathrm{mg} / \mathrm{ml}$ stock solutions were prepared by weighing $10.56 \mathrm{mg}$ AMI hydrochloride (corresponding to $10 \mathrm{mg}$ AMI) on a Metler Toledo AB 54-S balance which was dissolved in $10 \mathrm{ml}$ of methanol, respectively, $5.29 \mathrm{mg}$ of DEA hydrochloride (corresponding to $5 \mathrm{mg}$ of DEA) dissolved in $5 \mathrm{ml}$ of methanol. Standard work solutions, at 8 concentration levels, were prepared by diluting stock solutions with methanol over the concentration range of 25$2500 \mathrm{ng} / \mathrm{ml}$ for AMI and 2.5-1250 ng/ml for DEA. Also, 3 quality control samples (QC) of 75, 1250 and $2000 \mathrm{ng} /$ $\mathrm{ml}$ for AMI and 37.5, 625 and $1000 \mathrm{ng} / \mathrm{ml}$ for DEA were prepared.

\section{Plasma sample processing}

Rat plasma samples were collected by cardiac puncture, in EDTA anticoagulant vials. All procedures on experimental animals were performed in agreement with the Ethics Committee for Scientific Research of the University of Medicine and Pharmacy of Tîrgu Mureş. The plasma calibration curve was constructed on the concentration range of 5-500 $\mathrm{ng} / \mathrm{ml}$ plasma for AMI and 2.5-250 ng/ml plasma for DEA.

For the calibration curve and plasma QC samples, 120 $\mu \mathrm{l}$ rat plasma was spiked with $40 \mu \mathrm{l}$ AMI solution and 40 $\mu \mathrm{l}$ DEA solution. Plasma proteins were precipitated with $600 \mu \mathrm{l}$ methanol and the samples were vortex-mixed for 10 seconds. The mixture was centrifuged for 10 minutes at $10000 \mathrm{rpm} .500 \mu \mathrm{l}$ supernatant was transferred to a chromatography vial and $5 \mu \mathrm{l}$ were injected into the chromatographic system.

\section{Chromatographic conditions}

Separation of the compounds was performed on an Agilent 1100 Series System (Agilent Technologies, USA) consisting

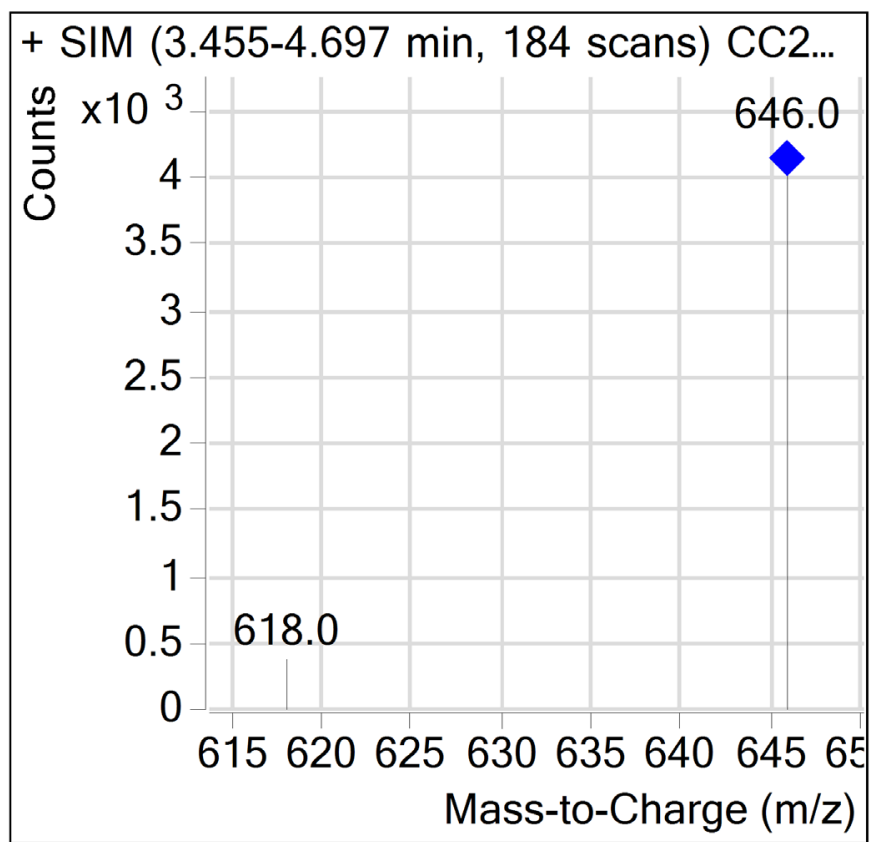

of a quaternary pump, solvent degasser, autosampler with controlled temperature, column thermostat and an Agilent 6410 QQQ mass spectrometer detector with ESI source. Separation was performed on a Kinetex $2.6 \mu \mathrm{m} \mathrm{C18} 100 \mathrm{x}$ $4.6 \mathrm{~mm}$ column. The mobile phase used for the separation consisted from acetonitrile and $0.1 \%$ formic acid in 65:35 isocratic mixture, with a flow rate of $0.5 \mathrm{ml} / \mathrm{min}$.

MS conditions:

- ionization type and mode: ESI+;

- nebulizer nitrogen: 40 psi;

- drying gas: nitrogen, flow rate $8 \mathrm{~L} / \mathrm{min}$;

source temperature $350^{\circ} \mathrm{C}$;

- capillary potential: $4000 \mathrm{~V}$;

- monitoring transitions m/z $646 \rightarrow 135$ for AMI and $618 \rightarrow 135$ for DEA.

\section{Results and discussions}

AMI determination was performed by molecular ion fragmentation $[\mathrm{M}+\mathrm{H}]^{+} \mathrm{m} / \mathrm{z} 646$ and DEA starting from $[\mathrm{M}+\mathrm{H}]^{+} \mathrm{m} / \mathrm{z} 618$ to the $\mathrm{m} / \mathrm{z} 135$ fragment for both compounds (Figure 1).

Chromatograms of rat plasma samples spiked with AMI and DEA at the lower limit of quantification (LLOQ) are presented in Figure 2 and 3. Compounds of interest are separated at a retention time of $3.94 \mathrm{~min}$ AMI and 3.16 min DEA.

\section{HPLC method performances}

\section{Specificity studies}

The specificity of the method was verified using 6 blanc rat plasma samples.

\section{Linearity studies}

3 calibration curves were prepared, with 8 concentration levels, in rat plasma and the medium calibration curves of

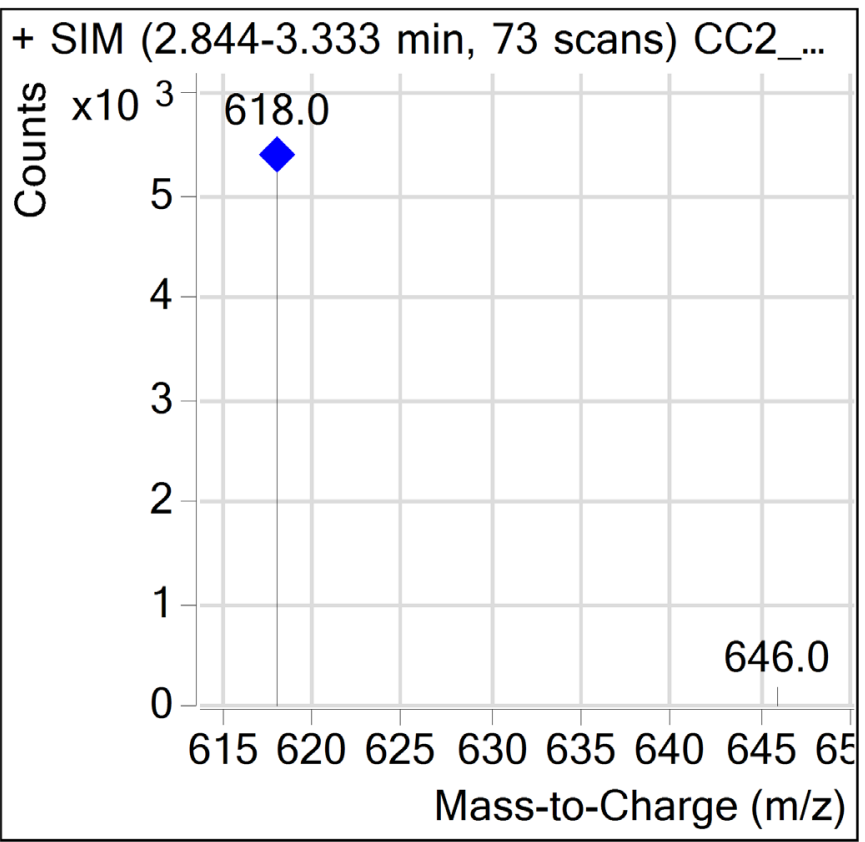

Fig. 1. Full-scan mass spectrum of AMI and DEA in the mobile phase 


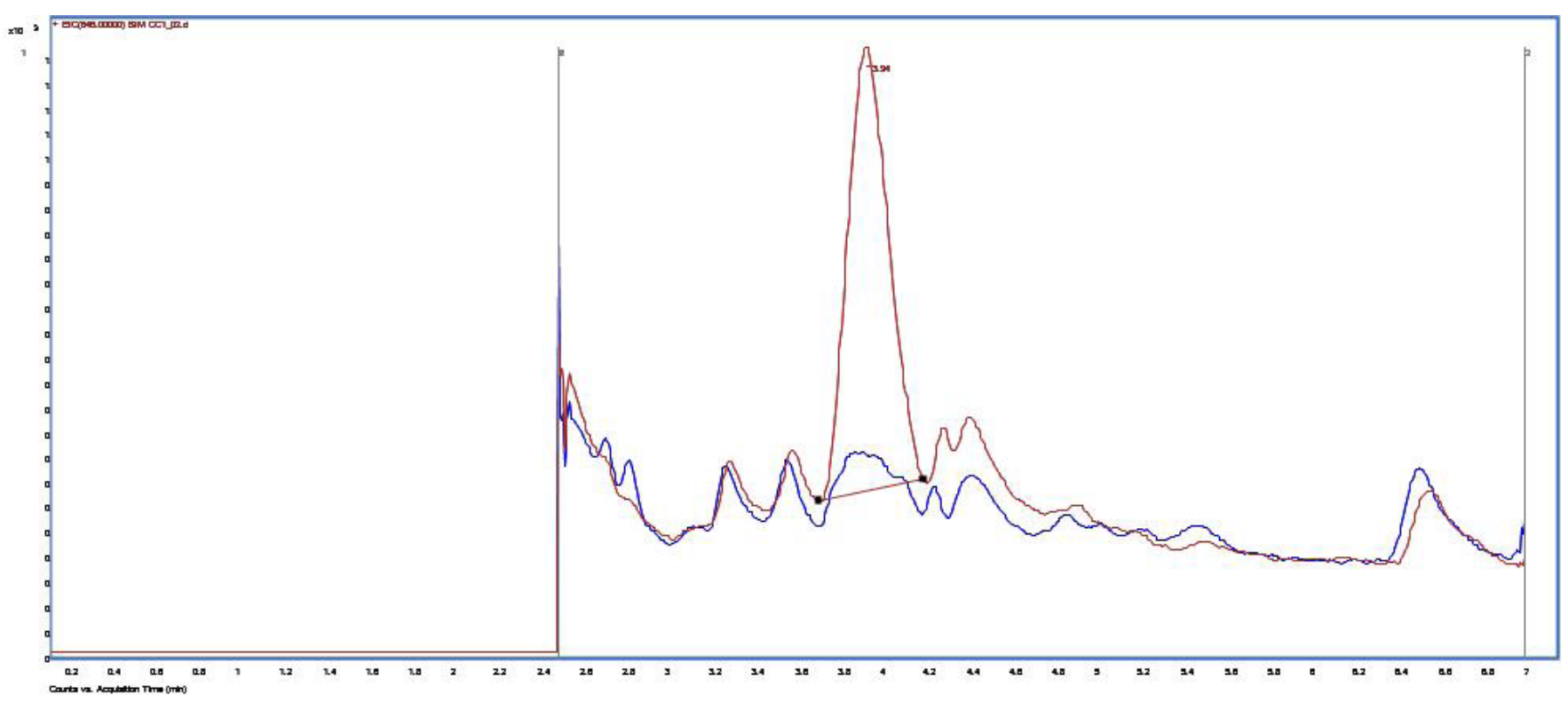

Fig. 2. Chromatogram of a blanc plasma sample (blue line) and an AMl-spiked sample at LLOQ (5 $\mathrm{ng} / \mathrm{ml}$ plasma)

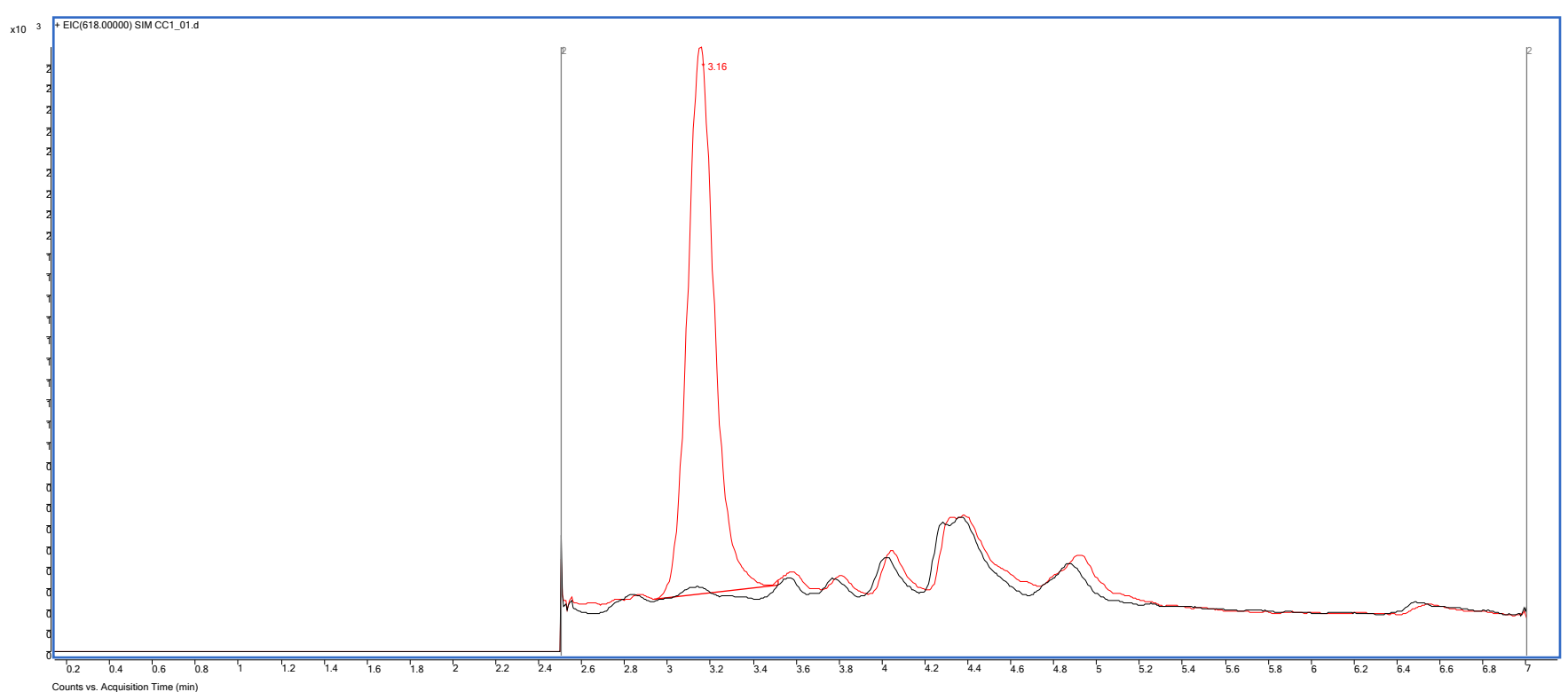

Fig. 3.- Chromatogram of a blank plasma sample (black line) and spiked with DEA at LLOQ (2.5 ng/ml plasma)

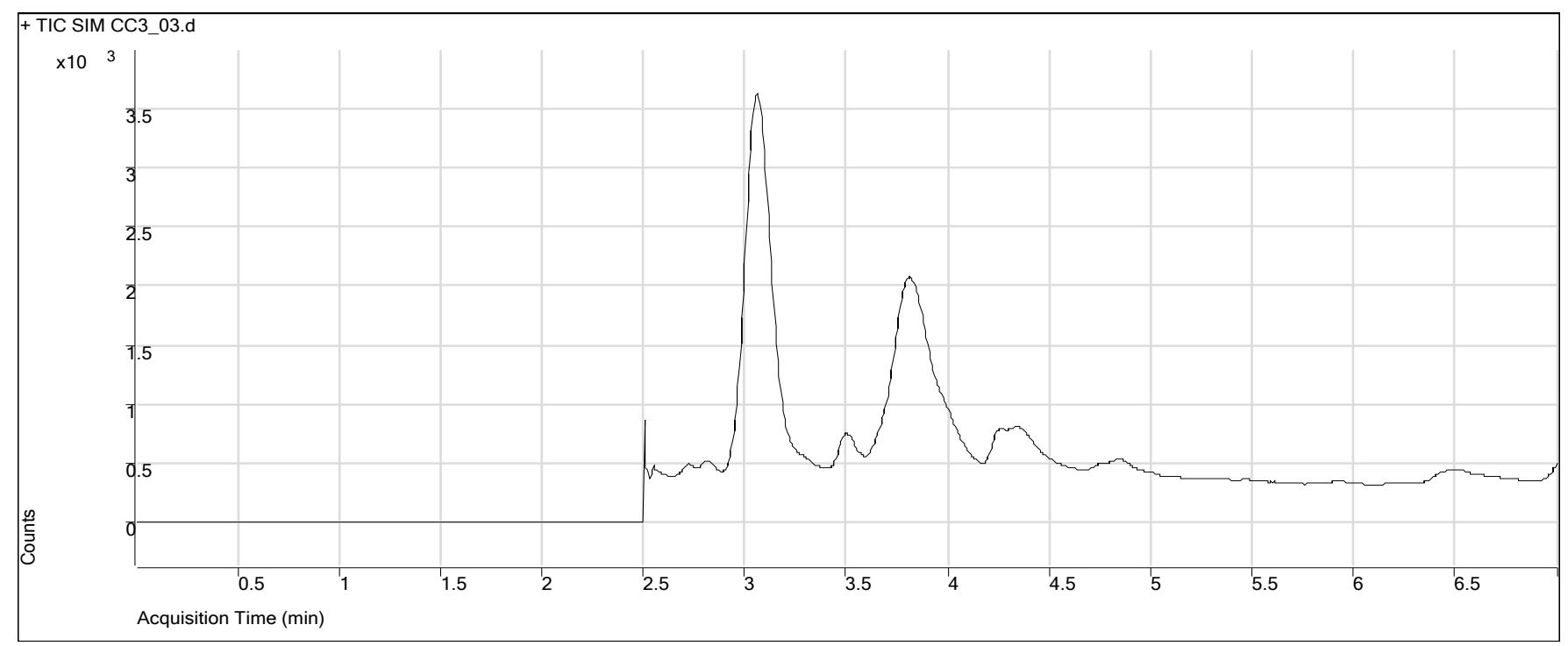

Fig. 4. Chromatogram of a rat plasma sample spiked with AMl and DEA at LLOQ (5 ng/ml plasma AMl and $2.5 \mathrm{ng} / \mathrm{ml}$ plasma DEA) 
$y=a( \pm S D) x+b( \pm S D)$ type, where $y$-concentration and $\mathrm{x}$-peak area, were $\mathrm{y}=1462.40( \pm 72.95) \mathrm{x}+4679.66$ $( \pm 2400.32)$ for AMI with a determination coefficient $\mathrm{R}^{2}>$ 0,99 and $y=1464.20( \pm 129.51) x+15907.33( \pm 3803.84)$ for DEA with a determination coefficient $\mathrm{R}^{2}>0.99$.

Residuals distribution was random and within $\pm 15 \%$ limits. The results demonstrated a good fitting calibration model over the selected concentration range and in accordance to bioanalysis quality criteria.

\section{Precision and accuracy}

The precision within- and between-run (CV\%) and accuracy $(\mathrm{Bias} \%)$ were determined during the same series and on different days, on 5 individual LLOQ, QCA, QCB and QCC samples, at concentrations of 5, 15, 250, $400 \mathrm{ng} / \mathrm{ml}$ plasma AMI and 2.5, 7.5, 125, $200 \mathrm{ng} / \mathrm{ml}$ plasma DEA, according to validation guidelines.

The method presents a good accuracy $(101.45 \%$ between-run and $98.57 \%$ within-run for DEA and $97.68 \%$ within-run and $104.76 \%$ between-run for AMI) and precision for both compounds (9.4\% within-run and $11.12 \%$ between-run for AMI and $13.56 \%$ within-run and $14.23 \%$ between-run for DEA) (Table I and II).

LLOQ was set at $5 \mathrm{ng} / \mathrm{ml}$ plasma AMI and $2.5 \mathrm{ng} / \mathrm{ml}$ plasma DEA, therefore the LC-MS method developed for AMI and DEA determination in rat plasma presents a much lower LLOQ compared to methods already published in scientific literature $[7,8,9]$.

Starting from these premises, the developed method will be used in the study of AMI and DEA plasma levels following chronic treatment in rats undergoing a controlled weight gain/weight loss cycle and compared to a control group (with no significant fluctuations in weight during the experiment). The animal model was chosen according to the similar pharmacokinetic properties of AMI in the two species. Although the microsomal enzyme system differs between human and rat, DEA was confirmed as the active metabolite in both cases $[10,11]$.

As in the future we aim to determine the plasma concentrations of the two compounds at different time intervals, until complete elimination, an analytical method with increased sensitivity is required.

In addition, in order to demonstrate the applicability of analytical methods, animals received doses of AMI between 25 and $200 \mathrm{mg} / \mathrm{kg}$ bw (intraperitoneal or intravenous) in bolus; in efficacy and safety studies similar oral doses were administred. However, in the case of oral administration, the plasma concentrations obtained are much lower compared to those obtained after parenteral administration.

Although toxicity mechanisms may vary depending on the organ, numerous studies have shown that the occurrence of side effects is associated with the duration of treatment and excessive accumulation of AMI in the body.

Due to increased lipophilia, AMI is predominantly distributed in adipose tissue with a particular pharmacokinetics in obese patients with frequent cardiac abnormalities, obesity being associated with a pro-inflammatory condition and increased oxidative stress. Administration of AMI to these patients should be made with caution considering the individual variability of pharmacokinetics and the impossibility to monitor plasma concentrations during chronic treatment [12].

In weight-loss diets (obese patients with increased cardiovascular risk at which gradual weight loss is recommended), or in case of forced weight-loss (parenteral nutrition in patients unable to receive a balanced nutritional and caloric intake after myocardial infarction or stroke) by

Table I. Within- and between-run precision, accuracy and recovery for AMI $(n=5)$

\begin{tabular}{|c|c|c|c|c|c|c|}
\hline \multirow[t]{2}{*}{$\begin{array}{l}\text { C nominal } \\
\mathrm{ng} / \mathrm{ml}\end{array}$} & $\begin{array}{c}\text { Mean C } \\
\mathrm{ng} / \mathrm{ml}( \pm \mathrm{SD})\end{array}$ & $\begin{array}{c}\text { Recovery \% } \\
\text { ( } \pm \text { SD) }\end{array}$ & $\begin{array}{c}\text { CV\% } \\
\text { (Bias\%) }\end{array}$ & $\begin{array}{c}\text { Mean C } \\
\mathrm{ng} / \mathrm{ml}( \pm \mathrm{SD})\end{array}$ & $\begin{array}{c}\text { Recovery \% } \\
\text { ( } \pm \text { SD) }\end{array}$ & CV\% \\
\hline & \multicolumn{3}{|c|}{ Within-run } & \multicolumn{3}{|c|}{ Between-run } \\
\hline 5 & $\begin{array}{c}4.88 \\
( \pm 0.41)\end{array}$ & $\begin{array}{c}97.68 \\
( \pm 9.24)\end{array}$ & $\begin{array}{c}9.46 \\
(-2.32)\end{array}$ & $\begin{array}{c}5.23 \\
( \pm 0.58)\end{array}$ & $\begin{array}{c}104.76 \\
( \pm 11.65)\end{array}$ & $\begin{array}{l}11.12 \\
(4.76)\end{array}$ \\
\hline 15 & $15.08( \pm 0.86)$ & $100.51( \pm 5.16)$ & $\begin{array}{c}5.74 \\
(0.51)\end{array}$ & $14.36( \pm 1.73)$ & $95.76( \pm 10.34)$ & $\begin{array}{l}12.08 \\
(-3.37)\end{array}$ \\
\hline 250 & $284.52( \pm 3.73)$ & $113.81( \pm 1.33)$ & $\begin{array}{c}1.31 \\
(13,81)\end{array}$ & $283.19( \pm 8.89)$ & $113.27( \pm 3.18)$ & $\begin{array}{c}3.14 \\
(13.27)\end{array}$ \\
\hline 400 & $386.54( \pm 15.88)$ & $96.63( \pm 3.97)$ & $\begin{array}{c}4.1 \\
(-3,37)\end{array}$ & $401.80( \pm 23.00)$ & $100.45( \pm 5.75)$ & $\begin{array}{l}5.72 \\
(0.45)\end{array}$ \\
\hline
\end{tabular}

Table II. Within- and between-run precision, accuracy and recovery for DEA $(n=5)$

\begin{tabular}{|c|c|c|c|c|c|c|}
\hline \multirow[t]{2}{*}{$\begin{array}{l}\text { C nominal } \\
\mathrm{ng} / \mathrm{ml}\end{array}$} & $\begin{array}{c}\text { Mean C } \\
\mathrm{ng} / \mathrm{ml}( \pm \mathrm{SD})\end{array}$ & 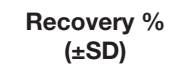 & $\begin{array}{c}\text { CV\% } \\
\text { (Bias\%) }\end{array}$ & $\begin{array}{c}\text { Mean C } \\
\mathrm{ng} / \mathrm{ml}( \pm \mathrm{SD})\end{array}$ & $\begin{array}{l}\text { Recovery \% } \\
\text { ( } \pm \text { SD) }\end{array}$ & $\begin{array}{c}\text { CV\% } \\
\text { (Bias\%) }\end{array}$ \\
\hline & \multicolumn{3}{|c|}{ Within-run } & \multicolumn{3}{|c|}{ Between-run } \\
\hline 2.5 & $\begin{array}{c}2.46 \\
( \pm 0.33)\end{array}$ & $98.57( \pm 13.37)$ & $\begin{array}{c}13.56 \\
(-1.43)\end{array}$ & $\begin{array}{c}2.35 \\
( \pm 0,45)\end{array}$ & $\begin{array}{c}101.45 \\
( \pm 14.52)\end{array}$ & $\begin{array}{l}14.23 \\
(1.45)\end{array}$ \\
\hline 7.5 & $\begin{array}{c}8.64 \\
( \pm 1.26)\end{array}$ & $115.33( \pm 15.08)$ & $\begin{array}{c}14.62 \\
(15.33)\end{array}$ & $\begin{array}{c}7.64 \\
( \pm 0.51)\end{array}$ & $101.90( \pm 6.87)$ & $\begin{array}{c}6.74 \\
(1.90)\end{array}$ \\
\hline 125 & $133.97( \pm 4.82)$ & $107.17( \pm 3.45)$ & $\begin{array}{l}3.59 \\
(7.17)\end{array}$ & $131.29( \pm 6.19)$ & $105.03( \pm 4.42)$ & $\begin{array}{c}4.71 \\
(5.03)\end{array}$ \\
\hline 200 & $194.14( \pm 3.12)$ & $97.07( \pm 1.56)$ & $\begin{array}{c}1.61 \\
(-2.83)\end{array}$ & $200.18( \pm 10.16)$ & $100.09( \pm 5.08)$ & $\begin{array}{l}5.07 \\
(0,09)\end{array}$ \\
\hline
\end{tabular}


modifying the insulin/glucagon ratio in favor of glucagon, gluconeogenesis from amino acids and lipolysis is induced, the released fatty acids being used to maintain energy cell homeostasis [13]. In this case, AMI and DEA accumulated in the adipose tissue would be mobilized, raising problems both during chronic treatment, by increased plasma levels and toxicity, but also in case of discontinuation of treatment, complete elimination from the body requiers a longer period of time.

\section{Conclusions}

The LC-MS method developed to detect AMI and DEA from rat plasma was sensitive and accurate, with an LLOQ (5 $\mathrm{ng} / \mathrm{ml}$ for AMI, $2.5 \mathrm{ng} / \mathrm{ml}$ for DEA), therefore suitable for pharmacokinetic studies, including low doses of substances originated from the adipose tissue deposits and found in plasma after massive lipolysis.

\section{Author's contribution}

BEÖ - Conceptualization

GJ - Investigation

$\mathrm{SzV}$ - Methodology

AM - Validation

ATV - Writing - original draft

\section{Conflict of interest}

None to declare

\section{References}

1. Schleifer JW, Sorajja D, Shen WK - Advances in the pharmacologic treatment of ventricular arrhythmias. Expert Opin Pharmacother.
2015;16(17):2637-51

2. Lu JT, Cai Y, Chen F, Jia WW, Hu ZY, Zhao YS - A Physiologically Based Pharmacokinetic Model of Amiodarone and its Metabolite Desethylamiodarone in Rats: Pooled Analysis of Published Data. Eur $\mathrm{J}$ Drug Metab Pharmacokinet. 2016 Dec;41(6):689-703.

3. Roden AC, Camus P - latrogenic pulmonary lesions. Semin Diagn Pathol. 2018 Jul;35(4):260-271.

4. Schumacher JD, Guo GL - Mechanistic review of drug-induced steatohepatitis. Toxicol Appl Pharmacol. 2015 Nov 15;289(1):40-7.

5. Santangeli P, Di Biase L, Burkhardt JD, Bai R, Mohanty P, Pump A, Natale A - Examining the safety of amiodarone. Expert Opin Drug Saf. 2012 Mar;11(2):191-214.

6. Lafuente-Lafuente C, Alvarez JC, Leenhardt A, Mouly S, Extramiana F, Caulin C, Funck-Brentano C, Bergmann JF - Amiodarone concentrations in plasma and fat tissue during chronic treatment and related toxicity. $\mathrm{Br}$ J Clin Pharmacol. 2009 May;67(5):511-9.

7. Shayeganpour A, Somayaji V, Brocks DR - A liquid chromatographymass spectrometry assay method for simultaneous determination of amiodarone and desethylamiodarone in rat specimens. Biomed Chromatogr. 2007 Mar; 21(3):284-90.

8. Najjar TA - Disposition of amiodarone in rats after single and multiple intraperitoneal doses.Eur J Drug Metab Pharmacokinet. 2001 JanJun;26(1-2):65-9.

9. Binkhathlan Z, Somayaji V, Brocks DR, Lavasanifar A - Development of a liquid chromatography-mass spectrometry (LC/MS) assay method for the quantification of PSC 833 (Valspodar) in rat plasma. J Chromatogr B Analyt Technol Biomed Life Sci. 2008 Jun 15;869(1-2):31-7.

10. Elsherbiny ME, El-Kadi AO, Brocks DR - The effect of betanaphthoflavone on the metabolism of amiodarone by hepatic and extrahepatic microsomes. Toxicol Lett. 2010 Jun 2;195(2-3):147-54.

11. Najjar TA - Disposition of amiodarone in rats after single and multiple intraperitoneal doses. Eur J Drug Metab Pharmacokinet. 2001 JanJun;26(1-2):65-9.

12. Pathak RK, Mahajan R, Lau DH, Sanders P - The implications of obesity for cardiac arrhythmia mechanisms and management. Can J Cardiol. 2015 Feb;31(2):203-10.

13. Haley MJ, Mullard G, Hollywood KA, Cooper GJ, Dunn WB, Lawrence $\mathrm{CB}$ - Adipose tissue and metabolic and inflammatory responses to stroke are altered in obese mice. Disease Models \& Mechanisms. 2017;10(10):1229-1243. 